\title{
THE LEAK PATHWAY: A PATHWAY IN FLUX
}

$$
\text { Ashley Monaco }{ }^{1} \text {, Ben Ovryn², Josephine Axis }{ }^{1}, \text { Kurt Amsler }^{1}
$$

1. Department of Biomedical Sciences

NYIT College of Osteopathic Medicine

Northern Boulevard

Old Westbury, NY

$$
11568
$$

USA

2. Department of Physics

NYIT

Northern Boulevard

Old Westbury, NY

$$
11568
$$

USA

Corresponding Author: Kurt Amsler

Department of Biomedical Sciences

NYIT College of Osteopathic Medicine

Northern Boulevard

Old Westbury, NY

11568

USA

Phone: 516-686-3716

Email: kamsler@nyit.edu 


\begin{abstract}
The epithelial cell tight junction structure is the site of the transepithelial movement of solutes and water between epithelial cells (paracellular permeability). Paracellular permeability can be divided into two distinct pathways, the Pore Pathway mediating the movement of small ions and solutes and the Leak Pathway mediating the movement of large solutes. Claudin proteins form the basic paracellular permeability barrier and mediate the movement of small ions and solutes via the Pore Pathway. The Leak Pathway remains less understood. Several proteins have been implicated in mediating the Leak Pathway, including occludin, ZO proteins, tricellulin, and actin filaments, but the proteins comprising the Leak Pathway remain unresolved. The properties of the Leak Pathway, such as its molecular mechanism, its regulation, and whether or not it has a size limit, remain controversial. This review will trace the evolution of the Leak Pathway concept from its origins, will discuss the current information about the properties of the Leak Pathway, and will discuss recent research suggesting a possible molecular basis for the Leak Pathway. Based on these findings, we propose a model for the molecular mechanism underlying the Leak Pathway and its regulation.
\end{abstract}

\title{
KEYWORDS
}

Paracellular permeability, tight junction, Pore Pathway, Leak Pathway, occludin, ZO-1, ZO-2, claudin 
The focus of this review article is to trace the development of the concept of a paracellular permeability pathway for large solutes, i.e., the Leak Pathway, and to discuss some recent results that may provide insights into the cellular and molecular basis for this pathway. We have attempted to provide a broad coverage of the topic but, of necessity, could not include all the relevant studies. We apologize in advance to all whose work was not included in the final version of this review article.

\section{THE TIGHT JUNCTION IS THE PARACELLULAR PERMEABILITY BARRIER}

The concept of a barrier, the "terminal bar", that restricts the movement of solutes and water through the paracellular pathway between epithelial cells dates back at least to Bizzozero [1]. Identification of the tight junction (zonula occludens) as the most apical portion of the terminal bar which restricts the paracellular movement of large molecules between body compartments separated by epithelial cell sheets was proposed by Farquhar and Palade [2]. Their pioneering experiments demonstrated by electron microscopy that hemoglobin and zymogen could not penetrate the lateral intercellular spaces beyond the tight junction structure in several epithelial tissues. They stated, "Hence the tight junction is impervious to concentrated protein solutions and appears to function as a diffusion barrier or 'seal'." Ussing and Windhager [3] demonstrated that chloride ions moved across the frog skin epithelium via the paracellular pathway to maintain charge neutrality following active sodium ion transport. This showed that the tight junction exhibited permeability to some solutes. Machen et al. [4] used lanthanum ions $\left(\mathrm{La}^{+3}\right)$ to examine the permeability of the tight junction in several epithelia. $\mathrm{La}^{+3}$ ions are not transported into cells and can be precipitated into the electron dense lanthanum sulfate which can be detected by electron microscopy [5]. They demonstrated that $\mathrm{La}^{+3}$ permeates the tight junctions of both intestinal and gallbladder epithelia, supporting the idea that the tight junction is the site of the epithelial tissue paracellular permeability pathway. It was previously shown that lanthanum ions did not permeate into the tight junctions of toad urinary bladder epithelia [4] and frog skin epithelia [6]. Based on these and other observations, Machen et al. [4] and Froemter and Diamond [7] proposed a categorization of epithelia as "leaky" or "tight". This designation continues to be used to this day. It is focused, however, on the relative permeability of the tight junction of different epithelial tissues to small ions, what has become known as the "Pore Pathway" (see below), and not to larger molecules.

\section{STRANDS, PORES, AND PARACELLULAR PERMEABILITY}

A molecular basis for the paracellular barrier function was suggested by the finding that freeze fracture electron microscopy revealed arrays of anastomosing strands composed of small particles running through the tight junction region at the immediate subapical region of the plasma membrane of epithelial cells [8, 9]. Multiple groups provided evidence that the leakiness of the paracellular permeability barrier was likely related to the structure/organization of these strands [see, e.g., 10,11]. Subsequent studies supported a correlation between tight junction strand number and epithelial tissue or monolayer transepithelial electrical resistance (TER), a measure of small ion permeability [see, e.g., 12, 13]. This led to the proposal that tight junction permeability was mediated by a continuous barrier, comprised of these branching strands, punctuated by some number of openings of a defined size which allow for small ion permeability. It was predicted that the number of these openings ("pores") varied between tight and leaky epithelia.

\section{SIZE SELECTIVITY OF PARACELLULAR PERMEABILITY}

Studies examining the effect of permeation enhancers, compounds that increase paracellular permeability, suggested that the increased paracellular permeability to large solutes was due to dilation of the tight junction structure leading to an increase in the size of the existing tight junction pores [see, e.g., 14, 15]. Alternative hypotheses to explain increases in paracellular 
permeability, such as increases in the number of tight junction pores or the existence of pores of different sizes, were also suggested [16]. Early attempts to determine the size of paracellular pores yielded widely variable results. Lindemann and Solomon [17] estimated a pore size of $\sim 4$ $\AA$ for the paracellular permeability of rat intestine based on the permeability of a range of small nonelectrolytes ranging from formamide (Stokes radius $-\sim 2 \AA$ ) to sucrose (Stokes radius $-\sim 4.5$ $\AA$ ). Madara and Dharmsathaphorn [18], examining the paracellular permeability of inulin (Stokes radius $-\sim 14 \AA$ ), mannitol (Stokes radius $-\sim 4 \AA$ ), and sodium in T84 intestinal epithelial cell monolayers, estimated that the tight junction pores had a radius of between $3.6 \AA$ and $15 \AA$. Ma et al. [19] suggested that rat colon possessed paracellular pores with an upper size limit of between $11 \AA$ and $15 \AA$ based on the permeability of inulin. Knipp et al. [20] estimated a pore size of $\sim 5 \AA$ in Caco- 2 intestinal epithelial cell monolayers by measuring the permeability of a range of small solutes.

\section{TWO PARACELLULAR PERMEABILITY PATHWAYS: THE PORE PATHWAY AND THE LEAK PATHWAY}

The possibility of multiple pathways mediating solute movement across epithelia was first suggested by Durbin et al. [21]. They reported the presence of two permeability pathways across frog gastric mucosa with pore sizes of $2.5 \AA$ and $60 \AA$. Van Os et al. [22] reported that rabbit gallbladder exhibited both an aqueous pathway for small electrolytes with a pore radius of $\sim 4 \AA$ and a second "shunt" pathway for larger nonelectrolytes with a radius of $\sim 40 \AA$. These early studies, however, did not discriminate between transcellular and paracellular permeability pathways. In an elegant series of experiments, Watson et al. [23] examined the paracellular permeability of polyethylene glycols (PEGs) of a range of sizes (Stokes radii $-3.47 \AA$ to $7.39 \AA$ ) in two intestinal epithelial cell lines, Caco-2 and T84. Plotting their results for PEG flux rate as a function of PEG radius revealed a biphasic behavior with a rapid decline in flux rate as $P E G$ radius increased up to $\sim 4 \AA$ followed by a slower rate of decrease as PEG radius increased further. This biphasic behavior indicated the presence of, at least, two permeability pathways. The first pathway exhibited a pore radius of $\sim 4.5 \AA$ and a high capacity. This component was proposed to represent the high capacity, size- and charge-selective pathway for the paracellular movement of small ions and solutes, "the Pore Pathway". Measurement of TER under appropriate conditions is often used as a surrogate marker for Pore Pathway permeability. A high TER indicates low paracellular ion permeability, whereas, a low TER indicates a relatively high paracellular ion permeability. The second pathway exhibited a low capacity and did not exhibit any solute size discrimination within their experimental setup; this pathway has come to be known as "the Leak Pathway". It is possible that the Leak Pathway may exhibit a size limit if the permeability of solutes with radii substantially larger than the largest PEG used in the Watson et al. [23] study, 7.39 $\AA$, is examined.

\section{TIGHT JUNCTION PROTEINS}

Studies from many groups have begun to compile a list of proteins associated with the tight junction (see Figure 1a). The first protein shown to be associated with the tight junction structure was Zonula Occludens-1, ZO-1 [24]. ZO-1 is a cytoplasmic protein that binds to the cytoplasmic surface of the tight junction structure and links it to F-actin filaments [25, 26]. Further studies identified two related proteins, ZO-2 and ZO-3, which are also associated with the tight junction structure cytoplasmic surface $[27,28,29]$. The first transmembrane protein found to be associated with the tight junction structure was occludin [30]. Occludin is a member of the MARVEL (MAL and related proteins for vesicle trafficking and membrane link) protein family that also includes Marvel D3 and tricellulin. These proteins, which form the Tight junction-Associated Marvel Protein (TAMP) subfamily, are all localized preferentially to the tight junction structure [31]. Occludin and Marvel D3 are localized preferentially to bicellular tight junctions (sites where 
a)

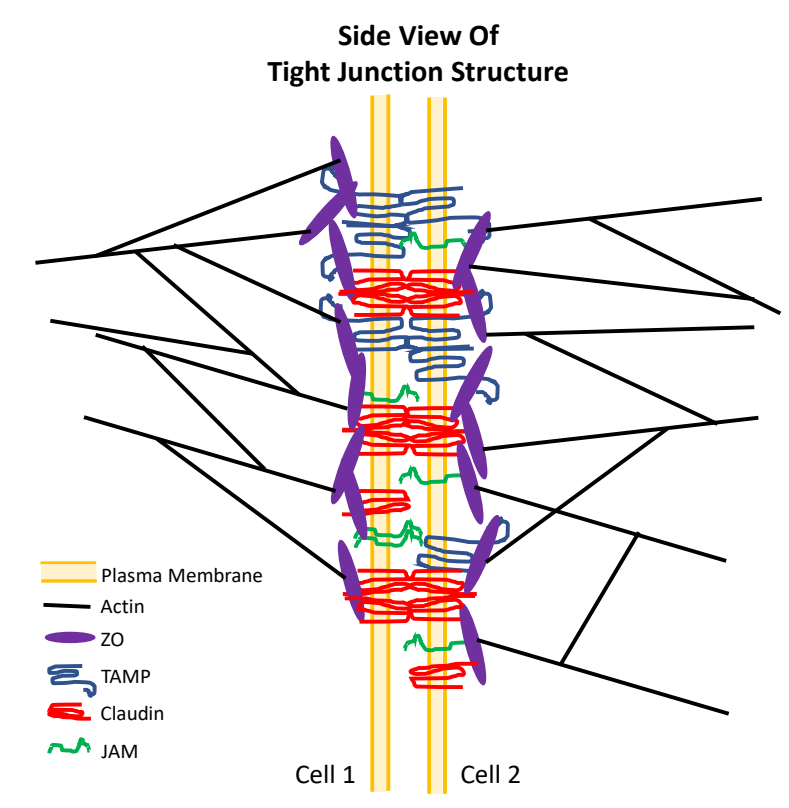

En Face View of

Cell 1 Tight Junction

Structure

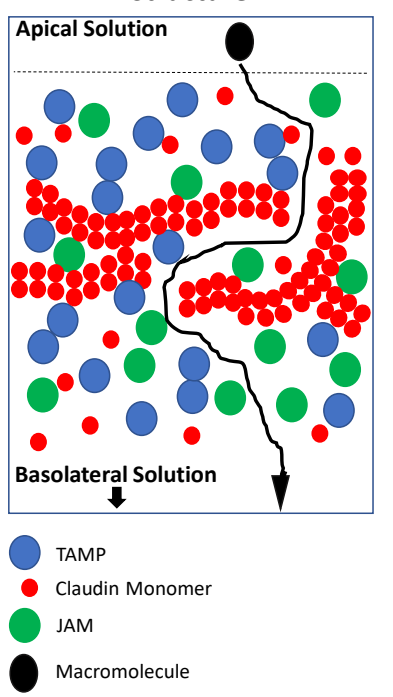

b)
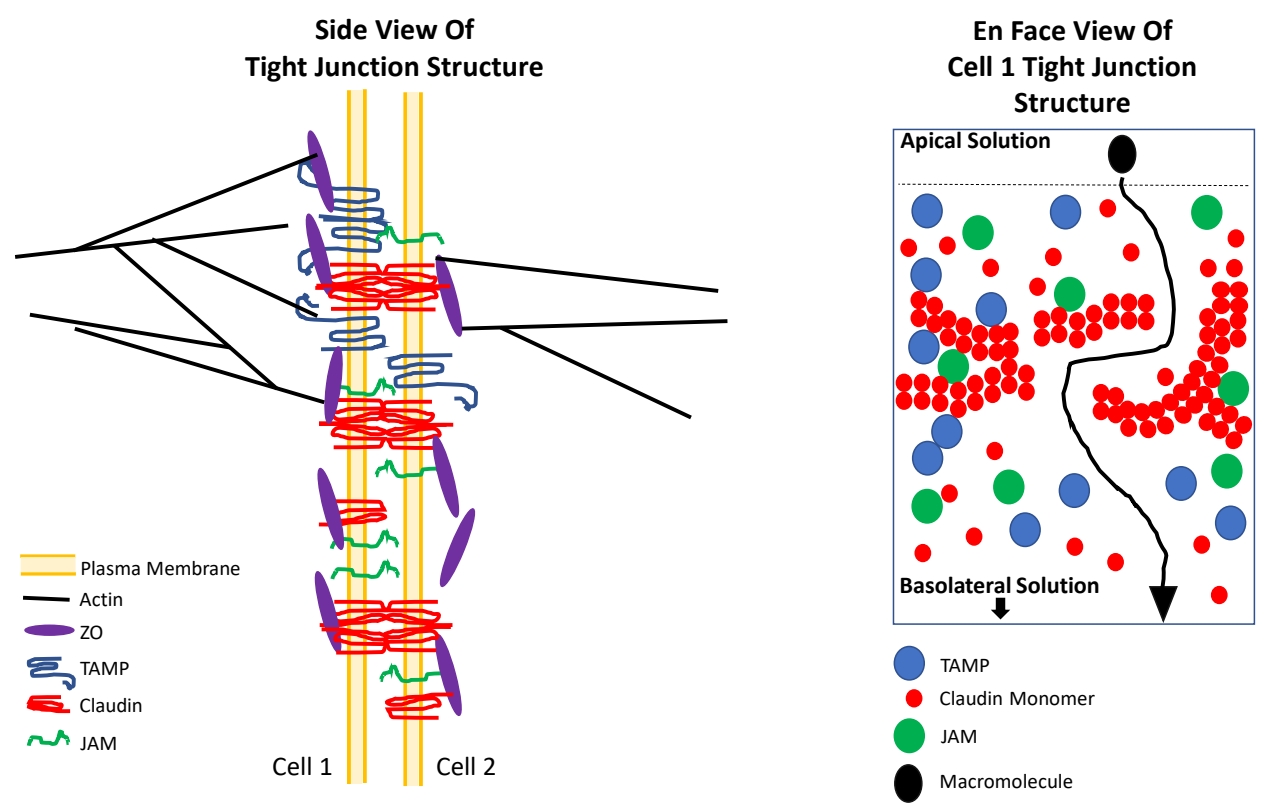

Figure 1. Model of tight junction supramolecular organization. Under control conditions (a) the tight junction protein are extensively crosslinked (left hand panel). Macromolecules traverse the tight junction through a tortuous pathway (right-hand panel) leading to low Leak Pathway permeability. Stimuli that decrease tight junction protein crosslinking (b) induce loss of occludin and ZO proteins at the tight junction (left-hand panel) and a "relaxing" of the tight junction protein lattice (right-hand panel). This combination of factors increases the size and number of "breaks" in the claudin strands and increased porosity of the overall tight junction membrane protein lattice structure (right-hand panel), thereby increasing Leak Pathway permeability. 
two cells meet), whereas, tricellulin is localized preferentially to tricellular tight junctions (sites where three cells meet) [32]. Angulin proteins (angulin 1, angulin 2, and angulin 3) are also localized preferentially to tricellular tight junctions [33, 34]. Junctional Adhesion Molecules (JAMs), members of the immunoglobulin superfamily of proteins, are localized preferentially to bicellular tight junction sites [35]. The first two members of the claudin family of transmembrane proteins (claudin-1 and claudin-2), which form the strands critical for generating the paracellular barrier, were cloned in 1998 [36]. The claudin protein family has grown to include 27 members [37] that exhibit cell type-specific and tissue-specific expression patterns. In addition to this array of core tight junction proteins, a large number of cytoplasmic proteins has been shown to associate with the tight junction. These include cingulin [38] and an ever-expanding array of adaptor proteins, signaling proteins, cytoskeletal proteins, and regulatory proteins [see, e.g., 39, 40]. The roles of these transmembrane proteins and cytoplasmic proteins in the structure, function, and regulation of the tight junction is an ongoing focus of study.

Tight junction proteins exhibit a range of homophilic and heterophilic binding interactions. For example, claudins in apposing epithelial cell plasma membranes bind together (trans interactions) to form the paracellular pores that mediate the transepithelial movement of small ions and solutes via the Pore Pathway (see below). Occludin exhibits trans-homophilic binding interactions [41]. Occludin, tricellulin, and MarvelD3 exhibit homophilic binding interactions within the same plasma membrane (cis-interactions). MarvelD3 also exhibits cis-heterophilic binding interactions with occludin and tricellulin. Some claudins exhibit cis-oligomerization with TAMPs. JAM-A exhibits homophilic cis-binding interactions [42]. ZO proteins heterodimerize forming ZO-1/ZO-2 or ZO-1/ZO-3 dimers via their PDZ2 domains [25, 28, 43]. ZO proteins function as scaffolding proteins connecting the tight junction membrane proteins to the cytoskeleton and to various signaling proteins. The ZO proteins possess binding sites for many of the primary tight junction membrane proteins, including claudins (via the PDZ1 domain [36, $43]$ ), occludin (via the U5/GUK domain [25, 44]), tricellulin [32], and JAM-A (via the PDZ3 domain and SH3 domain $[45,46])$. ZO proteins also possess binding sites for actin (via the actin binding region), actin organizing proteins such as TOCA-1 (via the PDZ1 domain [47]), actinbinding proteins such as $\alpha$-actinin-4 (via the PDZ-1 domain [48]) and cortactin (via a C-terminal domain [49]), and other cytoskeletal elements [see, e.g., 50, 51]. These many-fold cis and trans binding events, both homophilic and heterophilic, support the hypothesis that the tight junction structure is a highly organized supramolecular complex of transmembrane and cytoplasmic proteins that is crosslinked to the actin cytoskeleton and, likely, to the microtubule network (Figure 1a) [see, e.g., 40, 52, 53]. In addition, many studies have demonstrated posttranslational modifications of tight junction proteins, e.g., phosphorylation, correlated with changes in tight junction protein binding events and barrier function [see, e.g., 54, 55, 56, 57, 58, 59].

\section{WHICH PROTEINS FORM THE PARACELLULAR PERMEABILITY BARRIER?}

Multiple studies support a role for claudins as critical components forming the paracellular permeability barrier. Expression of claudin-1 and claudin-2 in mouse L fibroblasts, which do not express claudins, do not form tight junctions, and do not exhibit strands in freeze fracture electron microscopy, led to the appearance of membrane strands in freeze fracture that were very similar in appearance to those observed in epithelia [60]. Treatment of either MDCK Type I renal epithelial cells (high TER), which normally express claudins and form tight junction strands, or claudin-3-transfected L cells with Clostridium perfringens enterotoxin, which extracts claudin-3 and claudin-4 from the tight junctions, led to the loss of tight junction strands [61]. Extraction of claudin-3 and claudin-4 was paralleled in MDCK Type I renal epithelial cells by an increase in the paracellular permeability of both small ions (decrease in TER) and some larger solutes (4 kDa fluorescein-dextran and $10 \mathrm{kDa}$ fluorescein-dextran) but not all larger solutes (40 
kDa fluorescein-dextran) [61]. One interpretation of these data is that it suggests a disruption of the tricellular permeability barrier since manipulation of tricellulin levels in MDCK Type II renal epithelial cells (low TER) and HT29 intestinal epithelial cells altered the paracellular permeability of $4 \mathrm{kDa}$ and $10 \mathrm{kDa}$ fluorescein-dextran but not of $20 \mathrm{kDa}$ fluorescein-dextran [62]. Incubation of T84 intestinal epithelial cells with a peptide comprising the distal half of the first extracellular loop of claudin-1 (Ser ${ }^{53}$ to $\mathrm{Thr}^{80}$ ) disrupted the tight junction localization of claudin-1, occludin, JAM-A, and ZO-1 and increased the paracellular permeability to both small ions (decreased TER) and large solutes (3 kDa fluorescein-dextran) [63]. Since the claudin-1 peptide dimerized in solution and bound to the extracellular domain of full-length claudin-1, it was proposed that claudin-1 homophilic interactions, either trans or cis, are critical for stabilizing the organization of tight junction proteins in the mature structure and, thereby, maintaining the paracellular permeability barrier.

\section{PORE PATHWAY VERSUS LEAK PATHWAY: THE SAME OR DIFFERENT?}

A major question is whether the Pore Pathway and the Leak Pathway represent two aspects of the same permeability pathway or represent distinct permeability pathways. One line of evidence comes from studies examining the function of claudins. As described above, expression of claudin- 1 and claudin- 2 in mouse $L$ fibroblasts results in the formation of membrane strands typical of the tight junction structure [60]. Since these initial studies, work by many groups has demonstrated that members of the claudin protein family contribute to the permeability barrier. In addition, some claudins can form cation pores or anion pores mediating the paracellular movement of small ions and small solutes [see, e.g., 37, 64, 65, 66, 67, 68]. For example, claudin-2, which is now known to be a cation pore-forming claudin, is the most extensively studied claudin. Overexpression of claudin-2 in MDCK Type II renal epithelial cells increased the paracellular flux of small polyethylene glycol oligomers but not of larger polyethylene glycol oligomers or mannitol [69]. Expression of claudin-2 in MDCK C7 (Type I) renal epithelial cells, which do not normally express claudin-2, produced a dramatic decrease in TER (increase in the movement of small cations) without a change in the permeability to either mannitol or lactulose [70]. Knockout of claudin-2 in MDCK Type II renal epithelial cells produced an increase in TER (decrease in permeability to small cations) but did not alter the permeability of larger solutes such as fluorescein and $4 \mathrm{kDa}$ fluorescein-dextran [71]. Knockout of claudin-2 in mice decreased the $\mathrm{Na}^{+}$permeability of the proximal tubule [72]. Interestingly, a recent x-ray crystallography study found that claudin- 2 forms a pore of $7.4 \AA$ [73], consistent with the studies (described above) determining the size limit of the Pore Pathway. Claudin-15 was shown to be a cation pore-forming claudin since knockout of claudin-15 in mice decreased intestinal paracellular $\mathrm{Na}^{+}$permeability [74]. Claudin-17 was found to be an anion pore-forming claudin. Expression of claudin-17 in MDCK C7 (Type I) renal epithelial cells increased paracellular anion permeability, while knockdown of claudin-17 in LLC-PK 1 renal epithelial cells decreased paracellular anion permeability [75].

In contrast to the pore-forming ability of the claudins described above, expression of some other claudins strengthens the paracellular permeability barrier to all solutes. For example, expression of claudin-3 in MDCK Type II renal epithelial cells decreased the paracellular permeability to cations and to non-charged solutes, including $4 \mathrm{kDa}$ fluorescein-dextran [76]. Expression of claudin-1 in MDCK Type II renal epithelial cells similarly increased TER and decreased the paracellular permeability to larger solutes, $4 \mathrm{kDa}$ fluorescein-dextran and $40 \mathrm{kDa}$ fluoresceindextran [77]. It is important to emphasize that all claudins contribute to maintaining the overall paracellular permeability barrier. Some claudins sole function is to strengthen this barrier, whereas, other claudins also form pores that mediate the paracellular permeability of specific small ions and solutes. 
Although not an exhaustive survey, these studies support the hypothesis that the claudins are critical components of the paracellular permeability barrier limiting the paracellular movement of both large and small solutes. In addition, the results support the hypothesis that the claudins form the size- and charge-selective pores that mediate the movement of small ions and solutes through the paracellular permeability barrier, i.e., the Pore Pathway. In contrast, the claudins do not mediate the movement of large solutes via the Leak Pathway. It is important to note that other tight junction and cytoplasmic proteins may affect Pore Pathway activity by modulating the ability of specific claudins to form pores [see, e.g., 56] or through other mechanisms. For more complete discussions of claudins, the reader is referred to Guenzel and Yu [78] and Piontek et al. [79].

A second line of evidence regarding regulation of paracellular permeability also supports the hypothesis that the Pore Pathway and the Leak Pathway represent distinct permeability mechanisms. Multiple studies have reported parallel changes in Pore Pathway permeability, typically assessed by measuring TER, and Leak Pathway permeability, typically assessed by measuring the flux of a large non-electrolyte substance such as mannitol or fluorescein-dextran, in response to different modulators in a variety of epithelia [see, e.g., 80, 81, 82, 83, 84, 85]. Many other studies, however, have found discordant regulation of the permeability to small versus large solutes. For example, RhoA activation both increased TER (decreased Pore Pathway permeability) and increased mannitol flux (increased Leak Pathway permeability) in MDCK Type II renal epithelial cells [86]. Using the PEG size profiling technique described above [23], it was shown that treatment of T84 intestinal epithelial cells with interferon- $\gamma$ increased Leak Pathway permeability while not affecting Pore Pathway permeability [87]. Treatment of MDCK Type II renal epithelial cells with interferon- $\gamma$ and tumor necrosis factor- $\alpha$ both increased TER (decreased Pore pathway permeability) and increased the paracellular flux of $3 \mathrm{kDa}$ fluorescein-dextran [88]. Cao et al. [82] reported that berberine treatment of Caco-2 intestinal epithelial cells increased TER (decreased Pore Pathway permeability) but had no effect on the flux rate of $4 \mathrm{kDa}$ fluorescein-dextran. Carattino et al. [89] demonstrated that stretch of bladder epithelial umbrella cell monolayers produced a dramatic increase in Pore Pathway permeability but did not alter the permeability to larger solutes. Mercado et al. [90] examined the effects of five nutraceuticals (zinc, quercetin, indole, butyrate, and nicotine) on Pore Pathway and Leak Pathway permeability in the LLC-PK 1 renal epithelial cell line. They found no consistent concordance in the effects of these compounds on the Pore Pathway and the Leak Pathway. Fan et al. [55] recently reported that treatment of T84 intestinal epithelial cells with interleukin-22 produced parallel changes in Pore Pathway and Leak Pathway flux rate but treatment with interleukin-17A decreased TER while not altering the flux rate of $4 \mathrm{kDa}$ fluorescein-dextran. We have shown that treatment of both MDCK Type II renal epithelial cells and LLC-PK 1 renal epithelial cells with low concentrations of hydrogen peroxide increased Leak Pathway permeability without altering TER [91]. These results examining multiple epithelial cell types using a variety of modulators demonstrate differential and independent regulation of the Pore Pathway and the Leak Pathway. The results are most consistent with the hypothesis that the Pore Pathway and the Leak Pathway are distinct paracellular permeability pathways.

\section{DOES THE LEAK PATHWAY HAVE A SIZE LIMIT?}

Even as the molecular basis and functional properties of the Pore Pathway are under intense investigation and are being rapidly elucidated, the properties of the Leak Pathway have remained relatively unclear. Since the initial identification of the Leak Pathway as the paracellular permeability route for large solutes, it has most often been hypothesized to represent small, transient breaks in the tight junction structure [see, e.g., 92]. The reported lack of a size limit for the Leak Pathway would seem to fit with this "Rip" hypothesis. This issue has not, however, been investigated systematically. Many studies have utilized only one or a few 
solutes to measure Leak Pathway permeability. While providing information about relative permeability changes upon a manipulation, the studies provide little information about the possible size limit of the Leak Pathway. Most studies have examined the permeability of solutes with Stokes radii in the range from mannitol $(\sim 4 \AA)$ to $4 \mathrm{kDa}$ fluorescein-dextran $(\sim 14 \AA)$. Some studies, however, have measured significant epithelial cell paracellular permeability for solutes with Stokes radii of $30 \AA$ or larger [see, e.g., 81, 93].

The simplest mathematical analysis of paracellular permeability assumes passage of solutes through pores which are uniform cylinders, with pore radius, $R$, and solutes which are spherical with radius, $r$, and diffusion constant, $D$. The mathematical representation is given by the Stokes-Einstein equation

$$
D=\frac{k_{B} T}{6 \pi \eta r}
$$

where $k_{B}$ is the Boltzmann's constant, $T$ is the temperature and $\eta$ is the solution viscosity. The radius $r$ is often referred to interchangeably as the Stokes radius or molecular radius. This analysis assumes the pore radius is much larger than solute the Stokes radius such that the solute does not interact with the pore opening or walls while transiting the pore.

If this condition cannot be assumed, estimates of pore size from measurements of solute permeability rely on a mathematical analysis which assumes that solute flux is related to diffusion by Fick's law and is restricted as the molecule encounters the pore. The simplest assumption states that all molecules will enter the pore if they do not hit the pore's edge and this occurs provided the center of the molecule enters within a circle of radius $=R-r$. An often cited model $[94,95]$ states that in addition to this simple steric hindrance, the molecule is further impeded by frictional effects such that the permeability, $P$, is given by:

$$
P(r)=\frac{\epsilon}{\delta} D F\left(\frac{r}{R}\right)
$$

where $\varepsilon$ is the volume fraction of pores, $\delta$ is the length of a pore and $F(r / R)$ is often called the Renkin equation [96]:

$$
F\left(\frac{r}{R}\right)=\frac{\epsilon}{\delta}\left(1-\frac{r}{R}\right)^{2}\left(1-2.104 \frac{r}{R}+2.09\left(\frac{r}{R}\right)^{3}-0.95\left(\frac{r}{R}\right)^{5}\right)
$$

For very small solutes $(r \rightarrow 0)$ or very large pores $(R \rightarrow \infty), F\left(\frac{r}{R}\right) \rightarrow 1$ and $P(r) \rightarrow \frac{\epsilon}{\delta} D$, i.e., reduces to Fick's First Law of Diffusion. Conversely, for large $r$ or small pore size, $F\left(\frac{r}{R}\right)$ becomes vanishingly small which indicates that the permeability is severely limited. In general, the use of the Renkin equation has been questioned when the ratio of solute Stokes radius to pore radius is greater than $0.3-0.4[20,23,97]$. Furthermore, this form of the Renkin equation (Eq. 3) assumes that the molecule only undergoes diffusive transport, but it has been shown that it may be important to model the effect of laminar flow which will modify the form of Eq. 3 .

Using this formalism, Kim and Crandall [95] measured the permeability of a range of solutes (water $-1.5 \AA$ to raffinose $-6.1 \AA$ ) across bullfrog alveolar epithelia. They reported two populations of pores. A majority population of small pores with a radius of $5 \AA$ and a minority population of large pores with a radius of $50 \AA$. Cavanaugh et al. [99], measuring the permeability of a series of small molecules (methylamine $-1.5 \AA$ to leucine-leucine $-5.5 \AA$ ) across rat alveolar Type I epithelial cell monolayers, estimated the radius of a population of 
large pores to be $43 \AA$. Kawedia et al. [98] estimated a Leak Pathway pore size of $58 \pm 7.4 \AA$ in salivary epithelial cell monolayers by measuring the paracellular permeability of mannitol and raffinose $(\sim 6 \AA)$. Buschmann et al. [81] measured the paracellular flux of fluorescein $(\sim 4.5 \AA)$ and fluorescein-dextrans up to $40 \mathrm{kDa}(\sim 45 \AA)$ in wild type Caco-2 intestinal epithelial cells and in Caco-2 cells in which occludin protein was knocked down. By quantitating the differences in fluxes for each solute between the wild type and occludin knockdown Caco-2 intestinal epithelial cells, they concluded that an occludin-dependent paracellular permeability pathway had a pore size of $\sim 62.5 \AA$. However, it is unclear if this would represent the Leak Pathway pore size itself

\section{TABLE 1. CALCULATION OF THE PRODUCT OF $P_{\text {app }}$ AND KINEMATIC VISCOSITY FOR A RANGE OF FLUORESCEIN-DEXTRAN SIZES}

\begin{tabular}{|c|c|c|c|c|}
\hline $\begin{array}{l}\text { Fluorescein- } \\
\text { Dextran }\end{array}$ & $\begin{array}{l}\text { Stokes } \\
\text { Radius } \\
\quad(\AA)\end{array}$ & $\begin{array}{c}\mathbf{P a p p}_{\text {app }} \\
{[(\mathbf{A} / \mathbf{s})]}\end{array}$ & $\begin{array}{c}\text { Kinematic } \\
\text { Viscosity }(v) \\
{\left[\left(\AA^{2} / s\right) \times 10^{14}\right]}\end{array}$ & $\begin{array}{c}\text { Papp }_{\text {a Kinematic }} \\
\text { Viscosity } \\
\left(\mathbf{P}_{\text {app }}\right) \\
{\left[\left(\AA^{3} / \mathbf{s}^{2}\right) \times 10^{14}\right]}\end{array}$ \\
\hline $4 \mathrm{kDa}$ & 14 & $2.93 \pm 0.71$ & $0.9614 \pm 0.0066$ & $2.8169 \pm 0.6829$ \\
\hline $10 \mathrm{kDa}$ & 23 & $1.20 \pm 0.41$ & $0.9835 \pm 0.0102$ & $1.1802 \pm 0.4034$ \\
\hline $20 \mathrm{kDa}$ & 33 & $1.07 \pm 0.29$ & $0.9860 \pm 0.0065$ & $1.0550 \pm 0.2860$ \\
\hline $40 \mathrm{kDa}$ & 45 & $0.59 \pm 0.16$ & $1.0380 \pm 0.0048$ & $0.6124 \pm 0.1661$ \\
\hline $70 \mathrm{kDa}$ & 60 & $0.33 \pm 0.17$ & $1.1168 \pm 0.0087$ & $0.3685 \pm 0.1898$ \\
\hline
\end{tabular}

Stokes radii for the fluorescein-dextrans are obtained from the Sigma technical document

(https://www.sigmaaldrich.com/technical-documents/protocols/biology/fluorescein-isothiocyanate-dextran.html). Kinematic viscosity was measured using an Ubbelohde-type viscometer (Cannon R56) according to the manufacturer's instructions. Flux rates for the fluorescein-dextrans were measured according to Caswell et al. [100]. Papp values of the fluorescein-dextrans were calculated from the measured flux rates according to Van Itallie et al. [69] and presented as mean \pm standard deviation of between 8 and 12 independent flux experiments.

or the effect occludin knockdown has on the Leak Pathway pore size.

We have recently carried out an analysis of the Leak Pathway pore size in MDCK Type II renal epithelial cells. The paracellular flux rates of fluorescein-dextrans ranging from $4 \mathrm{kDa}$ to $70 \mathrm{kDa}$ were measured at a constant concentration of $80 \mu \mathrm{M}$. The flux for all measured fluoresceindextrans, measured as described previously [100], was linear with time. Pooled data from these experiments, converted to $P_{\text {app }}$ values as described by Van Itallie et al. [69], are presented in Table 1 along with the Stokes radius of each fluorescein-dextran. Also shown are the kinematic viscosities $(v)$ of the fluorescein-dextran solutions measured using an Ubbelohde-type viscometer.

Although it may readily be observed from Table 1 that the permeability decreases with increasing Stokes radius, a quick calculation reveals that the decline in permeability with increasing pore size is faster than would be expected if permeability was simply via pure diffusion, indicating that the pore restricts the solute movement. If the pore did not restrict solute movement, Eqs. 1 - 3 predict that the permeability, $P(r)$ or $P_{a p p}$, would be governed by

$$
P(\mathrm{r})=\frac{\epsilon}{\delta} \frac{\mathrm{k}_{\mathrm{B}} \mathrm{T}}{6 \pi v \rho \mathrm{r}}=\mathrm{c} \frac{1}{v \mathrm{r}}
$$


where $v=\frac{\eta}{\rho}, \rho$ is the density (with $\rho=1000 \mathrm{~kg} / \mathrm{m}^{3}$ ), and $\mathrm{c}=\frac{\epsilon}{\delta} \frac{\mathrm{k}_{\mathrm{B}} \mathrm{T}}{6 \pi \rho}$ is a constant for a fixed set of experimental conditions. Therefore, for an infinitely large pore, the permeability is limited by diffusion and varies as $(v r)^{-1}$. On the other hand, if the pore becomes a limiting factor in the solute diffusion due to solute interactions with the pore opening and walls, then the permeability should be slower than $(v \mathrm{r})^{-1}$. Using the values presented in Table 1 for two solutes (4 kDa and

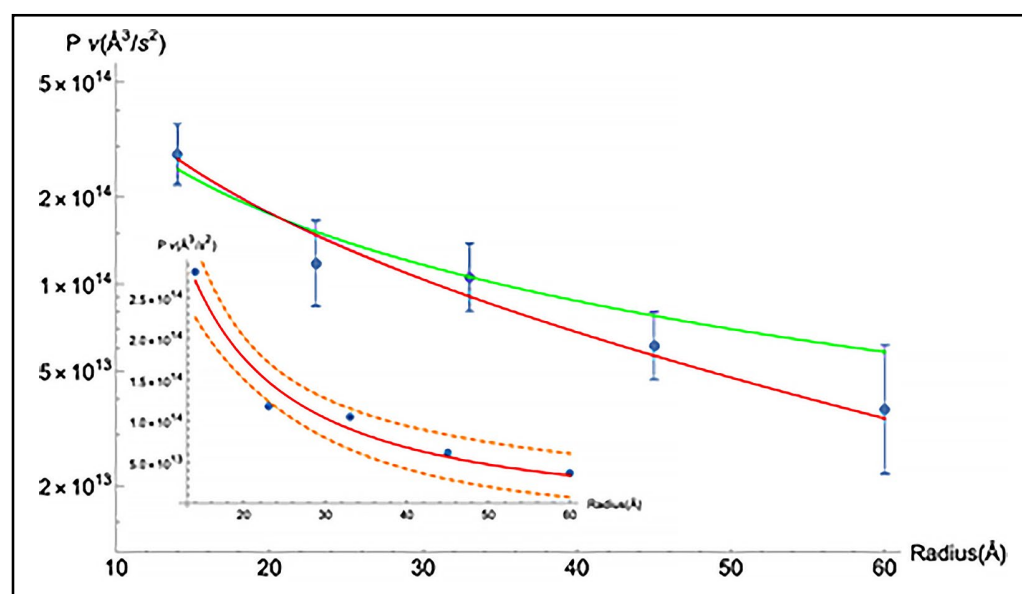

Figure 2. Plot of the data, $\mathrm{Papp} v$, from Table 1 (blue dots) and the "best-fit" to variations of Eq. 2 and Eq. 4 as given by $P(r) v(r)=$ $\alpha \frac{1}{r} F\left(\frac{r}{\beta}\right)$ (red curve) and $P(r) v(r)=\alpha \frac{1}{r}$ (green curve), respectively. Inset shows that the non-linear least squares fit falls with the $90 \%$ confidence interval. This fit predicts a pore radius of $r=362 \AA$.
$70 \mathrm{kDa}$ fluorescein-dextran), the ratios of the permeabilities and $v$ r are: $\mathrm{P}_{4 \mathrm{kDa}} / \mathrm{P}_{70 \mathrm{kDa},} \approx 8.88$ and $(v \mathrm{r})_{70 \mathrm{kDa}} /(v \mathrm{r})_{4 \mathrm{kDa}} \approx 4.98$, respectively. Therefore, the functional dependence of the permeability with radius declines faster than the product of viscosity and Stokes radius which supports the hypothesis that the Leak Pathway is mediated by openings/pores that limit the movement of solutes of this size range.

In order to determine if the permeability is restricted by the pore for all solute sizes as predicted by Eqs. 2 and 3, we used the values in Table 1 to plot the product of the permeability

and the kinematic viscosity $\left(\mathrm{P}_{\text {app }} v\right)$ versus the solute Stokes radius and attempted to fit the data with variations of Eq. 2 and Eq. 4 as given by $\mathrm{P}(\mathrm{r}) v(\mathrm{r})=\alpha \frac{1}{\mathrm{r}} \mathrm{F}\left(\frac{\mathrm{r}}{\beta}\right)$ or $\mathrm{P}(\mathrm{r}) v(\mathrm{r})=\alpha \frac{1}{\mathrm{r}}$, respectively where $\alpha$ and $\beta$ are fitting parameters. Figure 2 shows a non-linear least squares fit with $\mathrm{P}(\mathrm{r}) v(\mathrm{r})=\alpha \frac{1}{\mathrm{r}} \mathrm{F}\left(\frac{\mathrm{r}}{\beta}\right)$ (red curve) with $\alpha=45 \times 10^{14} \AA^{4} / \mathrm{s}^{2}$ and $\beta=362 \AA$ and $a$ fit with $\mathrm{P}(\mathrm{r}) v(\mathrm{r})=\alpha \frac{1}{\mathrm{r}}$ and $\alpha=35 \times 10^{14} \AA^{4} / \mathrm{s}^{2}$ (green curve). The inset demonstrates that the nonlinear least squares fit falls within the $90 \%$ confidence interval. The fit predicts that the pore has radius, $R=362 \AA$. This prediction for the radius of the pore in the Leak Pathway is substantially larger than the pore sizes reported by Kawedia et al. [98] and Buschmann et al. [81]. It is, however, more consistent with a pathway capable of mediating the paracellular permeability of solutes with Stokes radii of $60 \AA$ or larger.

\section{WHAT ARE THE MOLECULAR COMPONENTS OF THE LEAK PATHWAY?}

Occludin. Studies examining the effect on paracellular permeability of knockout of occludin protein expression in mice or knockdown of occludin protein content in cultured cells have produced differing results. Schulzke et al. [101] reported no effect of occludin knockout on intestinal mannitol flux. Epithelial cells derived from embryonic stem cells in which occludin expression was knocked down did not exhibit a major change in permeability to NHS-LC-biotin [102]. However, since NHS-LC-biotin is a linear molecule, it is unclear whether permeability to this solute would assess Pore Pathway or Leak Pathway permeability. Yu et al. [103] reported that permeability of MDCK Type II renal epithelial cells to either $3 \mathrm{kDa}$ fluorescein-dextran or 10 $\mathrm{kDa}$ fluorescein-dextran was unaffected by occludin protein content. Using flux of the fluorescent molecule, calcein [100], we did not detect any effect of occludin protein knockdown 
in MDCK Type II renal epithelial cells on Leak Pathway permeability (Table 2, [104]). The ability of hydrogen peroxide to increase Leak Pathway permeability was, however, enhanced by occludin knockdown and diminished by occludin overexpression [91]. In contrast, occludin content had no effect on the ability of Src Family Kinases to increase the paracellular

TABLE 2. EFFECT OF TIGHT JUNCTION PROTEIN KNOCKDOWN/KNOCKOUT ON PARACELLULAR CALCEIN FLUX RATE.

\begin{tabular}{|c|c|c|c|}
\hline Cell Type & $\begin{array}{c}\text { Calcein Flux Rate } \\
\text { (pmoles calcein/cm²/hour) }\end{array}$ & $\begin{array}{c}\text { Number of } \\
\text { Measurements }\end{array}$ & $\begin{array}{c}\text { p Value } \\
\text { (compared to Wild } \\
\text { Type MDCK) }\end{array}$ \\
\hline Wild Type MDCK & $5.14 \pm 1.25$ & 51 & \\
\hline $\begin{array}{c}\text { Occludin } \\
\text { Knockdown MDCK }\end{array}$ & $5.01 \pm 1.19$ & 11 & 0.74302 \\
\hline $\begin{array}{c}\text { ZO-1 Knockdown } \\
\text { MDCK }\end{array}$ & $17.60 \pm 5.75$ & 20 & $7.24 \times 10^{-9}$ \\
\hline $\begin{array}{c}\text { ZO-2 Knockdown } \\
\text { MDCK }\end{array}$ & $5.36 \pm 1.17$ & 24 & 0.47884 \\
\hline $\begin{array}{c}\text { TOCA-1 Knockout } \\
\text { MDCK }\end{array}$ & $10.95 \pm 2.99$ & 7 & 0.00198 \\
\hline
\end{tabular}

The parental MDCK Type II renal epithelial cell line and the derived knockdown and knockout cell lines were obtained and characterized as described previously [104]. Calcein flux rates were measured as described by Caswell et al. [96]. Data are provided as the mean \pm standard deviation of the indicated numbers of samples. $p$ Values were calculated using a two-way t-test compared to the flux rate measured in wild type MDCK Type II renal epithelial cells.

permeability of calcein [100]. Van Itallie et al. [88] reported that overexpression of occludin enhanced and occludin knockdown diminished the ability of cytokines to alter TER and permeability of large solutes in MDCK Type II renal epithelial cells. Lack of an effect of occludin content on the permeability of fluorescein-dextrans across Caco-2 intestinal epithelial cell monolayers was reported by Richter et al. [105]. In contrast to the above findings, the paracellular permeability of $3 \mathrm{kDa}$ fluorescein-dextran [106] and mannitol [107] in MDCK Type II renal epithelial cells was reported to be increased by over-expression of occludin protein. Knockdown of occludin protein expression in Caco-2 intestinal epithelial cells increased paracellular permeability to larger solutes [81, 108]. Interestingly, one study [108] found that the extent of the increase in Leak Pathway permeability observed in occludin knockdown Caco-2 intestinal epithelial cells was greater with increasing solute size. Overexpression of occludin protein in mouse intestine diminished the ability of Tumor Necrosis Factor (TNF) to induce leak of bovine serum albumin across the intestinal epithelium [109]. The observed variability in the effect of manipulating occludin protein content suggests differences in the role of occludin protein in mediating and/or regulating Leak Pathway permeability depending on cell type or type of stimulus.

Studies examining the effect of expression of occludin mutants or protein fragments on paracellular permeability provide some insights into potential functional domains of the occludin protein. The occludin $\mathrm{COOH}$-terminal cytoplasmic tail has been shown to mediate inter-protein interactions as well as being involved in targeting occludin to the tight junction and development and maintenance of barrier function [see, e.g., 44, 106, 110, 111]. Expression of a $\mathrm{COOH}-$ terminal domain deletion mutant of occludin protein in MDCK Type II renal epithelial cells 
produced a dramatic increase in the paracellular flux of $4 \mathrm{kDa}$ fluorescein-dextran [106]. The Leak Pathway permeability increase was proportional to the level of expression of this mutant occludin protein. This occludin mutant exhibited a discontinuous distribution, rather than the typical continuous distribution, within the tight junction region, suggesting a possible basis for its effect on Leak Pathway permeability. In contrast, expression of mutant occludin protein in which portions of the first or second extracellular loop were deleted decreased paracellular permeability of mannitol and horseradish peroxidase in MDCK Type II renal epithelial cells [110]. These occludin protein mutants were distributed continuously around the tight junction but extended down the lateral membrane, suggesting inefficient incorporation into the tight junction structure. Addition of a synthetic peptide corresponding to the second extracellular loop of occludin protein, but not to the first extracellular loop, to Xenopus renal epithelial cells (A6) dramatically increased paracellular permeability to multiple solutes, mannitol, inulin, $3 \mathrm{kDa}$ fluorescein-dextran, and $40 \mathrm{kDa}$ fluorescein-dextran [111]. These studies strongly suggest that occludin protein is involved in mediating the Leak Pathway permeability and its regulation.

Tricellulin. Moderate overexpression of tricellulin in MDCK Type II renal epithelial cells, which express low levels of endogenous tricellulin, maintained a tricellular junction localization for the protein [62]. Moderate tricellulin overexpression decreased the paracellular permeability of both $4 \mathrm{kDa}$ fluorescein-dextran and $10 \mathrm{kDa}$ fluorescein-dextran but not of $20 \mathrm{kDa}$ fluorescein-dextran or horseradish peroxidase [62]. Knockdown of tricellulin protein content in HT29 intestinal epithelial cells, which express higher endogenous tricellulin levels, increased the paracellular permeability of both $4 \mathrm{kDa}$ fluorescein-dextran and $10 \mathrm{kDa}$ fluorescein-dextran [112]. These results suggest that the tricellular junction can form a paracellular channel/pore for molecules up to between $10 \mathrm{kDa}(23 \AA)$ and $20 \mathrm{kDa}(33 \AA)$. Tricellulin protein limits the permeability via this pathway.

Junctional Adhesion Molecules. Knockdown of JAM-1 (JAM-A) in SK-CO15 colonic epithelial cells increased permeability via both the Pore Pathway (decreased TER) and the Leak Pathway (increased permeability to $4 \mathrm{kDa}$ fluorescein-dextran) [113]. Consistent with this result, the intestinal permeability to both small ions and $4 \mathrm{kDa}$ fluorescein-dextran was increased in JAM-A knockout mice [114]. Both systems also showed increased permeability to larger solutes up to $40 \mathrm{kDa}$ fluorescein-dextran [115]. These results indicate that JAM-A has a general role in maintaining the epithelial barrier function but, likely, does not have a selective role in mediating or regulating paracellular permeability via the Leak Pathway.

ZO Proteins. Knockdown of ZO-1 protein expression in MDCK Type II renal epithelial cells increased selectively the permeability to large solutes (Leak Pathway), including polyethylene glycol, mannitol, and $3 \mathrm{kDa}$ fluorescein-dextran [50]. Consistent with these findings, Tokuda et al. [116] reported that complete knockout of ZO-1 protein expression in MDCK Type II renal epithelial cells had no consistent effect on TER but produced a variable increase in permeability to $4 \mathrm{kDa}$ fluorescein-dextran. Van Itallie et al. [50] reported that knockdown of ZO-2 protein expression in MDCK Type II renal epithelial cells, in contrast, did not affect either TER or permeability to large solutes. We have confirmed an effect of ZO-1 knockdown but not of ZO-2 knockdown on Leak Pathway permeability in MDCK Type II renal epithelial cells (Table 2) [104]. However, Hernandez et al. [117] reported that knockdown of ZO-2 protein expression in MDCK Type II renal epithelial cells increased paracellular permeability to $70 \mathrm{kDa}$ fluorescein-dextran but did not affect TER. Raya-Sandino et al. [93] reported that knockdown of ZO-2 protein in MDCK Type II renal epithelial cells decreased paracellular permeability to $10 \mathrm{kDa}$ fluoresceindextran and $70 \mathrm{kDa}$ fluorescein-dextran and increased TER. Double knockdown of both ZO-1 and ZO-2 protein expression in MDCK Type II renal epithelial cells did not alter TER but dramatically increased the paracellular flux of $3 \mathrm{kDa}$ fluorescein-dextran [118]. Re-expression of 
full-length ZO-1 protein in these double knockdown MDCK cells restored the flux of $3 \mathrm{kDa}$ fluorescein-dextran to near wild type levels. In the ZO-1/ZO-2 double knockdown MDCK cells, expression of ZO-1 mutant proteins containing targeted deletions of specific protein domains revealed that the PDZ1, PDZ2, SH3, and U5 domains were most critical for ZO-1 to limit Leak Pathway permeability [119].

Actin Cytoskeleton. Many studies support a role for the actin cytoskeleton in regulation of epithelial barrier function [see, e.g., 120, 121, 122]. Recent evidence provides support for a role of the actin cytoskeleton in the selective regulation of the epithelial Leak Pathway permeability barrier. Van Itallie et al. [47] reported that ZO-1 binds to TOCA-1, a BAR-domain containing protein involved in formation of branching F-actin networks [123], and targets TOCA-1 protein to the tight junction. Knockout of TOCA-1 protein expression in MDCK Type II renal epithelial cells produced an increase in the permeability of $3 \mathrm{kDa}$ fluorescein-dextran while not affecting TER [47], similar to the effect of ZO-1 knockdown or knockout in these cells. Further supporting a role for formation of F-actin branching networks in the regulation of Leak Pathway permeability, treatment of MDCK Type II renal epithelial cells with the Arp2/3 inhibitor, CK666, increased the permeability to $3 \mathrm{kDa}$ fluorescein-dextran and this effect was synergistic with TOCA-1 knockout [47]. In addition, treatment of either ZO-1 knockdown [50, 104] or TOCA-1 knockout [104] MDCK Type II renal epithelial cells with blebbistatin, which inhibits myosin ATPase activity, increased paracellular permeability to large solutes. In contrast, treatment of wild type MDCK Type II renal epithelial cells with blebbistatin had no effect on permeability of either calcein or 3 kDa fluorescein-dextran [50, 104].

Claudins. As discussed above, claudins are a primary component of the paracellular permeability barrier. In addition, data indicate they mediate solute movement via the Pore Pathway. They do not, however, mediate solute movement via the Leak Pathway.

\section{WHAT IS THE LEAK PATHWAY?}

The Leak Pathway cannot represent a generalized weakening of the epithelial paracellular permeability barrier around every epithelial cell since this would lead to increased flux of both large and small solutes. As shown by experiments examining the effect of epithelial barrier disruption (e.g., through incubation with EDTA), this would result in a dramatic decrease in TER as the barrier to the movement of small ions is eliminated. Since many studies demonstrate that epithelial paracellular permeability to large solutes versus small ions and solutes does not necessarily change in parallel (see above), this indicates the Leak Pathway must, instead, represent a limited number of localized regions of the tight junction exhibiting increased permeability for large solutes. It is likely that these localized regions may not exist on every cell at any single time point. Two recent studies demonstrating a small number of discrete sites where macromolecules cross the tight junction lend strong support for this concept of the Leak Pathway [124, 125]. Stephenson et al. [125] reported that sites of solute permeation were transient, remaining open for no more than 5 minutes. Richter et al. [124] also reported that macromolecule permeability at some sites was transient, being "open" for 30 minutes or less. They also reported that treatment of HT29 intestinal epithelial cells with Tumor Necrosis Factor$\alpha$, which increases Leak Pathway permeability, increased the number of sites of macromolecule passage within the cell monolayer without increasing the amplitude of the flux through each site. These results suggest the Leak Pathway may be a dynamic and highly regulated aspect of normal epithelial cell physiology.

The claudins are a critical component forming the paracellular permeability barrier but do not mediate the movement of large solutes via the Leak Pathway. The studies described above have identified a number of proteins that may be involved in mediating the Leak Pathway 
including occludin, tricellulin, ZO-1, and the actin cytoskeleton. Many fundamental questions about the Leak Pathway, however, remain. What is the functional role of the Leak Pathway? How do these (and other) proteins form this paracellular permeability pathway for large solutes? And how is the Leak Pathway regulated?

A recent report may provide some insight into the molecular basis for the Leak Pathway and how it may be regulated. Stephenson et al. [125] studied the maintenance of tight junctions in the embryonic epithelium of the Xenopus laevis embryo. They demonstrated that localized disruptions of the tight junction occurred at sites of increased tension caused by junction elongation as cells in the embryo divided. These sites exhibited decreased contents of both ZO1 and occludin proteins, but not of claudin-6, followed by localized activation of RhoA. This led to localized actin polymerization and recruitment of ZO-1, occludin, and claudin- 6 proteins to the site. Recruitment of these proteins led to reinforcement of the tight junction and repair of the paracellular permeability barrier breach. This suggests the Leak Pathway represents a small number of sites of transient tight junction weakening within a population of epithelial cells that allows the passage of large solutes and macromolecules across the epithelial cell layer. These leaks were rapidly repaired (within $\sim 5$ minutes) by actomyosin-mediated concentration of tight junction proteins. Richter et al. [105, 124] have also reported data suggesting the Leak Pathway permeability represents movement of macromolecules through a limited number of sites within a cell population. These weakened areas of the tight junction correspond to sites of increased stress/tension on the tight junction structure. Multiple studies have documented an effect of physical stress on paracellular permeability. Cyclic stress increased the paracellular permeability of rat alveolar Type I epithelial cells $[99,126,127,128]$ and Caco-2 intestinal epithelial cells [129]. Osmotic stress increased the paracellular permeability of Caco-2 intestinal epithelial cells [130]. Cattaneo et al. [131] attributed collapse of domes in MDCK Type II renal epithelial cell cultures exposed to shear stress to increased paracellular permeability although they did not measure paracellular permeability directly. Cavanaugh et al. [99] and Cohen et al. [126] concluded that the effect of stretch increased the number of large pores without significantly changing the pore radius. Since these analyses assumed a constant pore length without any independent measurements, these conclusions must be regarded as tentative. We have observed that treatment of MDCK Type II renal epithelial cells with hydrogen peroxide, which increases Leak Pathway permeability, also increases cell twisting and movement (data not shown), similar to the effects of cell division described by Stephenson et al. [125]. In this context, it is interesting to note the marked parallels between regulation of tight junction and adherens junction integrity. These include junctional tensile stress (tight junction - [125]; adherens junction - [132]), localized RhoA activation (tight junction - [121]; adherens junction [132]), p114RhoGEF activation (tight junction - [133]; adherens junction - [132]), Ga12 activation (albeit in opposite directions; tight junction - [134]; adherens junction - [132]), mDia1 organization of actin structures (tight junction and adherens junction - [135]), and a tension sensor which transitions between a closed and an open conformation that exposes protein binding sites (tight junction (ZO-1) - [136]; adherens junction ( $\alpha$-catenin) - [137]). These similarities could represent a convergent evolution of regulatory mechanisms for the two junctional structures or, alternatively, an overlap in the mechanisms regulating the two junctional structures.

As diagrammed in Figure 1a, the tight junction structure is a highly crosslinked two-dimensional macromolecular lattice coupled to the cytoskeleton [see, e.g., 92, 138]. As described above, the extensive crosslinks include both lateral binding interactions between tight junction membrane proteins and crosslinking of tight junction membrane proteins through cytoplasmic scaffolding proteins. The claudins form an anastomosing double stranded network, as suggested by Krystofiak et al. [139] and Suzuki et al. [140]. Occasional breaks in the network are present, 
perhaps due to the presence of occludin [41]. The TAMPs are interspersed within and outside the claudin network, in some cases bound to the claudins via ZO protein crosslinking. The ZO proteins link the tight junction membrane protein network to the cytoskeleton and stabilize the network to resist tensile stress-induced disruption. Macromolecules traverse the tight junction structure by passing through successive breaks in the claudin strands as well as sufficiently large gaps in the overall protein lattice.

Our speculative model of Leak Pathway permeability suggests that any stimulus which decreases the extent of interconnection among the tight junction proteins or, possibly, the interaction of tight junction proteins with the cytoskeleton could cause a "relaxing" of the macromolecular lattice leading to increased breaks in the claudin network and increased porosity (Figure $1 \mathrm{~b}$ ). If this occurs at a small number of sites within a cell population, as suggested by the studies of Richter et al. [105, 124] and Stephenson et al. [125], this would lead to increased Leak Pathway permeability without altering Pore Pathway permeability. If these interactions are disrupted on a more global scale, however, this would lead to increases in the tight junction permeability to both macromolecules and small ions and solutes as these solutes cross the epithelium through these large disruptions of the tight junction structure. Recent studies have correlated changes in Leak Pathway permeability with mobility of occludin or other tight junction proteins [see, e.g., 56, 81, 91, 141, 142, 143]. Assuming changes in mobility would correlate with decreased tight junction structure stability and increased porosity, increased tight junction protein mobility would occur only at the sites of the weakening of tight junction protein crosslinking. If this occurs at a small number of sites within a cell population, this would likely not be detected by assessment of protein mobility at random sites within the cell population. Therefore, it would be necessary to identify the sites of increased Leak Pathway permeability and assess tight junction protein mobility specifically at those sites versus at sites not associated with increased Leak Pathway permeability. Stimuli that produce a more global weakening of tight junction protein crosslinking would lead to a generalized increase in the mobility of one or more tight junction proteins. Weakening of the tight junction protein crosslinking could occur through a variety of mechanisms including imposition of external tensile stress, changes in the actomyosin cytoskeleton organization, activation of relevant signaling pathways, or through other mechanisms. Different stimuli may result in different extents of changes in the tight junction protein crosslinking and, thereby, in Leak Pathway permeability. While this speculative model leaves many details unresolved, it provides a framework that can guide future investigation. 


\section{ACKNOWLEDGEMENTS}

The authors would like to thank Dr. A. Fanning (University of North Carolina) for the kind gift of the ZO-1 knockdown MDCK Type II renal epithelial cell line and the ZO-2 knockdown MDCK Type II renal epithelial cell line. The authors would like to thank Dr. E.E. Schneeberger (Massachusetts General Hospital and Harvard Medical School) and Dr. C.M. Van Itallie (NHLBI) for the kind gift of the occludin knockdown MDCK Type II renal epithelial cell line. The authors would like to thank Dr. C.M. Van Itallie (NHLBI) for the kind gift of the TOCA-1 knockout MDCK Type II renal epithelial cell line. The authors would like to thank Dr. Ann L. Miller and Rachel E. Stephenson (University of Michigan) for their helpful critiques of a draft of this manuscript. Research results presented in this article were obtained with financial support from institutional funds and by NIH 1 R15 DK091749. Publication costs were supported from institutional funds.

\section{AUTHOR CONTRIBUTIONS}

Conceptualization - Kurt Amsler

Methodology - Kurt Amsler, Josephine Axis, Ashley Monaco

Formal Analysis - Kurt Amsler, Ashley Monaco, Ben Ovryn

Investigation - Ashley Monaco, Kurt Amsler, Josephine Axis

Resources - Kurt Amsler

Writing - Original Draft Preparation - Kurt Amsler, Ashley Monaco

Writing - Review \& Editing - Kurt Amsler, Ashley Monaco, Josephine Axis, Ben Ovryn

Visualization - Kurt Amsler, Ben Ovryn

Supervision - Kurt Amsler

Project Administration - Kurt Amsler

Funding Acquisition - Kurt Amsler

\section{CONFLICTS OF INTEREST}

The authors declare no conflict of interest. 


\section{REFERENCES}

1. Bizzozero G. Osservazioni sulla struttura degli epiteli pavimentosi stratificati. Rend Ist Lombardo Sce Lattere, Series II 1870 3:675, 1870

2. Farquhar MG, Palade GE. Junctional complexes in various epithelia. J Cell Biol 1963 17:375412. PMID:13944428. PMCID:PMC2106201.

3. Ussing $\mathrm{HH}$, Windhager EE. Nature of shunt path and active sodium transport path through frog skin epithelium. Acta Physiol Scand 1964 61:484-504. PMID:14209264.

4. Machen TE, Erlij D, Wooding FB. Permeable junctional complexes. The movement of lanthanum across rabbit gallbladder and intestine. J Cell Biol 1972 54:302-213. PMID:5040881. PMCID:PMC2108875.

5. Whittembury G, Rawlins FA. Evidence of a paracellular pathway for ion flow in the kidney proximal tubule. Electromicroscopic demonstration of lanthanum precipitate in the tight junction. Pfluegers Arch 1971 330:302-309. PMID:5004222.

6. Martinez-Palomo A, Erlij D, Bracho H. Localization of permeability barriers in the frog skin epithelium. J Cell Biol 1971 50:277-287. PMID:4329611.

7. Froemter E, Diamond J. Route of passive ion permeation in epithelia. Nature New Biol 1972 235:9-13. PMID:4502409.

8. Goodenough DA, Revel JP. A fine structural analysis of intercellular junctions in the mouse liver. J Cell Biol 1970 45:272-290. PMID:4105112.

9. Staehelin LA, Mukherjee TM, Williams AW. Freeze-etch appearance of the tight junctions in the epithelium of small and large intestine of mice. Protoplasma 1969 67:165-184.

PMID:5346995.

10. Humbert F, Grandchamp A, Pricam C, Perrelet A, Orci L. Morphological changes in tight junctions of Necturus Maculosus proximal tubules undergoing saline diuresis. J Cell Biol 1976 69:90-96. PMID:1254651. PMCID:PMC2110974.

11. Wade JB, Karnovsky MJ. Fracture faces of osmotically disrupted zonulae occludentes. J Cell Biol 1974 62:344-350. PMID:4473455. PMCID:PMC2109392.

12. Claude P, Goodenough DA. Fracture faces of zonulae occludentes from "tight" and "leaky" epithelia. J Cell Biol 1973 58:390-400. PMID:4199658.

13. Claude $P$. Morphological factors influencing transepithelial permeability: a model for the resistance of the zonula occludens. J Membr Biol 1978 39:219-232. PMID:641977.

14. Anderberg EK, Lindmark T, Artursson P. Sodium caprate elicits dilatations in human intestinal tight junctions and enhances absorption by the paracellular route. Pharm Res 1993 10:857-864. PMID:8321854. 
15. Shimizaki T, Tomita M, Sadahiro S, Hayashi M, Awazu S. Absorption-enhancing effects of sodium caprate and palmitoyl carnitine in rat and human colons. Dig Dis Sci 1998 43:641-645. PMID:9539662.

16. Karczewski J, Groot J. Molecular physiology and pathophysiology of tight junction III: Tight junction regulation by intracellular messengers: differences in response within and between epithelia. Am J Physiol:Gastrointest Liver Physiol 2000 279:G660-665. PMID:11005751.

17. Lindemann B, Solomon AK. Permeability of luminal surface of intestinal mucosal cells. $J$ Gen Physiol 1962 45:801-810. PMID:14465429. PMCID:PMC2195210.

18. Madara JL, Dharmsathaphorn K. Occluding junction structure-function relationships in a cultured epithelial monolayer. J Cell Biol 1985 101:2124-2133. PMID:3934178.

PMCID:PMC2114013.

19. Ma TY, Hollander D, Erickson RA, Truong H, Nguyen $\mathrm{H}$, Krugliak P. Mechanism of colonic permeation of inulin: is rat colon more permeable than small intestine? Gastroenterol 1995 108:12-20. PMID:7806033.

20. Knipp GT, Ho NF, Barsuhn CL, Borchardt RT. Paracellular diffusion in Caco-2 cell monolayers: effect of perturbation on the transport of hydrophilic compounds that vary in charge and size. J Pharm Sci 1997 86:1105-1110. PMID:9344165.

21. Durbin RP, Frank H, Solomon AK. Water flow through frog gastric mucosa. J Gen Physiol 1956 39:535-551. PMID:13295553.

22. Van Os $\mathrm{CH}$, de Jong MD, Slegers JFG. Dimensions of polar pathways through rabbit gallbladder epithelium. J Membr Biol 1973 15:363-382. PMID:4838041.

23. Watson CJ, Rowland M, Warhurst G. Functional modeling of tight junctions in intestinal cell monolayers using polyethylene glycol oligomers. Am J Physiol:Cell Physiol 2001 281:C388C397. PMID:11443038.

24. Stevenson BR, Siliciano JD, Mooseker MS, Goodenough DA. Identification of ZO-1: a high molecular weight polypopetide associated with the tight junction (zonula occludens) in a variety of epithelia. J Cell Biol 1986 103:755-766. PMID:3528172.

25. Fanning AS, Jameson B, Jesaitis LA, Anderson JM. The tight junction protein ZO-1 establishes a link between the transmembrane protein occludin and the actin cytoskeleton. $J$ Biol Chem 1998 273:29745-29753. PMID:9792688.

26. Itoh M, Nagafuchi A, Moroi S, Tsukita S. Involvement of ZO-1 in cadherin-based cell adhesion through its direct binding to alpha catenin and actin filaments. J Cell Biol 1997 138:181-192. PMID:9214391.

27. Gumbiner B, Lowenkopf T, Apatira D. Identification of a 160-kDa polypeptide that binds to the tight junction protein ZO-1. Proc Natl Acad Sci USA 1991 88:3460-3464. PMID:2014265.

28. Haskins J, Gu L, Wittchen ES, Hibbard J, Stevenson BR. ZO-3, a novel member of the MAGUK protein family found at the tight junction, interacts with ZO-1 and occludin. J Cell Biol 1998 141:199-208. PMID:9531559. 
29. Jesaitis LA, Goodenough DA. Molecular characterization and tissue distribution of ZO-2, a tight junction protein homologous to ZO-1 and the Drosophila discs-large tumor suppressor protein. J Cell Biol 1994 124:949-961. PMID:8132716.

30. Furuse M, Hirase T, Itoh M, Nagafuchi A, Yonemura S, Tsukita S. Occludin: a novel integral membrane protein localizing at tight junctions. J Cell Biol 1993 123:1777-1788. PMID:8276896.

31. Raleigh DR, Marchiando AM, Zhang Y, Shen L, Sasaki H, Wang YM, Long MY, Turner JR. Tight junction-associated MARVEL proteins marveld3, triceullin, and occludin have distinct but overlapping functions. Mol Biol Cell 2010 21:1200-1213. PMID:20164257.

PMCID:PMC2847524.

32. Ikenouchi J, Furuse M, Furuse K, Sasaki H, Tsukita S, Tsukita S. Tricellulin constitutes a novel barrier at tricellular contacts of epithelial cells. J Cell Biol 2005 171:939-945.

PMID:16365161. PMCID:PMC2171318.

33. Higashi T, Tokuda S, Kitajiri S, Masuda S, Nakamura H, Oda Y, Furuse M. Analysis of the 'angulin' proteins LSR1, ILDR1 and ILDR2-tricellulin recruitment, epithelial barrier function and implication in deafness pathogenesis. J Cell Sci 2013 126:966-977. PMID:23239027.

34. Masuda S, Oda Y, Sasaki H, Ikenouchi J, Higashi T, Akashi M, Nishi E, Furuse M. LSR defines cell corners for tricellular tight junction formation in epithelial cells. J Cell Sci 2011 124:548-555. PMID:21245199.

35. Martin-Padura I, Lostaglio S, Schneemann M, Williams, L, Romano M, Fruscella P, Panzeri A, Stoppacciato A, Ruco L, Villa A, Simmons D, Dejana E. Junctional adhesion molecule, a novel member of the immunoglobulin superfamily that distributes at intercellular junctions and modulates monocyte transmigration. J Cell Biol 1998 142:117-127. PMID:9660867.

PMCID:PMC2133024.

36. Furuse M, Fujita K, Hiiragi T, Fujimoto K, Tsukita S. Claudin-1 and -2: novel integral membrane proteins localizing at tight junctions with no sequence similarity to occludin. J Cell Biol 1998 141:1539-1550. PMID:9747647. PMCID:PMC2132999.

37. Tsukita S, Tanaka H, Tamura A. The claudins: From tight junctions to biological systems. Trends Biochem Sci 2019 44:141-152. PMID:30665499.

38. Citi S, Sabanay H, Jakes R, Geiger B, Kendrick-Jones J. Cingulin, a new peripheral component of tight junctions. Nature 1988 333:272-276. PMID:3285223.

39. Zihni C, Terry SJ. RhoGTPase signaling at epithelial tight junctions: bridging the GAP between polarity and cancer. Internat J Biochem Cell Biol 2015 64:120-125. PMID:25757376.

40. Zihni C, Mills C, Matter K, Balda MS. Tight junctions: from simple barriers to multifunctional molecular gates. Nat Rev Mol Cell Biol 2016 17:564-580. PMID:27353478.

41. Cording J, Berg J, Kaeding N, Bellmann C, Tscheik C, Westphal JK, Milatz S, Guenzel D, Wolburg H, Piontek J, Huber O, Blasig IE. In tight junctions, claudins regulate the interactions between occludin, tricellulin and marvelD3, which, inversely, modulate claudin oligomerization. $J$ Cell Sci 2013 126:554-564. PMID:23203797. 
42. Rehder D, Iden S, Nasdala I, Wegener J, Brickwedde MK, Vestweber D, Ebnet K. Junctional adhesion molecule-A participates in the formation of apico-basal polarity through different domains. Exp Cell Res 2006 312:3389-3403. PMID:16919624.

43. Itoh M, Furuse M, Morita K, Kubota k, Saitou M, Tsukita S. Direct binding of three tight junction-associated MAGUKs, ZO-1, ZO-2 and ZO-3, with the COOH termini claudins. J Cell Biol 1999 147:1351-1363. PMID:10601346.

44. Furuse M, Itoh M, Hirase T, Nagafuchi A, Yonemura S, Tsukita S, Tsukita S. Direct association of occludin with ZO-1 and its possible involvement in the localization of occludin at tight junctions. J Cell Biol 1994 127:1617-1626. PMID:7798316.

45. Ebnet K, Schulz CU, Meyer Zu Brickwedde MK, Pendl GG, Vestweber D. Junctional adhesion molecule interacts with the PDZ domain-containing proteins AF-6 and ZO-1. J Biol Chem 2000 275:27979-27988. PMID:10856295.

46. Nomme J, Fanning AS, Caffrey M, Lye MF, Anderson JM, Lavie A. The Src homology 3 domain is required for junctional adhesion molecule binding to the third PDZ domain of the scaffolding protein ZO-1. J Biol Chem 2011 286:43352-43360. PMID:22030291.

47. Van Itallie CM, Tietgens AJ, Krystofiak E, Kachar B, Anderson JM. A complex of ZO-1 and the BAR-domain protein TOCA-1 regulates actin assembly at the tight junction. Mol Biol Cell 2015 26: 2769-2787. PMID:26063734. PMCID:PMC4571337.

48. Chen VC, Li X, Perreault H, Nagy JI. Interaction of zonula occludens-1 (ZO-1) with alphaactinin-4: application of functional proteomics for identification of PDZ domain-associated proteins. J Proteome Res 2006 5:2123-2134. PMID:16944923.

49. Katsube T, Takahisa M, Ueda R, Hashimoto N, Kobayashi M, Togashi S. Cortactin associates with the cell-cell function protein ZO-1 in both Drosophila and mouse. J Biol Chem 1998 273:29672-29677. PMID:9792678.

50. Van Itallie CM, Fanning AS, Bridges A, Anderson JM. ZO-1 stabilizes the tight junction solute barrier through coupling to the perijunctional cytoskeleton. Mol Biol Cell 2009 20:39303940. PMID:19605556.

51. Van Itallie CM, Anderson JM. Architecture of tight junctions and principles of molecular composition. Semin Cell Dev Biol 2014 36:157-165. PMID:25171873. PMCID:PMC4254347.

52. Glotfelty LG, Zahs A, lancu C, Shen L, Hecht GA. Microtubules are required for efficient epithelial tight junction homeostasis and restoration. Am J Physiol:Cell Physiol 2014 307:C245C254. PMID:24920678.

53. Vasileva E, Citi S. The role of microtubules in the regulation of epithelial junctions. Tissue Barriers 2018 6:1539596. PMID:30395792.

54. Doerfel MJ, Huber O. Modulation of tight junction structure and function by kinases and phosphatases targeting occludin. J Biomed Biotechnol 2012 2012:807356. PMID:22315516. 
55. Fan S, Weight CM, Luissint A-C, Hilgarth RS, Brazil JC, Ettel M, Nusrat A, Parkos CA. Role of JAM-A tyrosine phosphorylation in epithelial barrier dysfunction during intestinal inflammation. Mol Biol Cell 2019 30:566-578. PMID:30625033.

56. Raleigh DR, Boe DM, Yu D, Weber CR, Marchiando AM, Bradford EM, Wang Y, Wu L, Schneeberger EE, Shen L, Turner JR. Occludin S408 phosphorylation regulates tight junction protein interactions and barrier function. J Cell Biol 2011 193:565-582. PMID:21536752.

57. Rao RK, Basuroy S, Rao VU, Karnaky KJ, Gupta A. Tyrosine phosphorylation and dissociation of occludin-ZO-1 and E-cadherin- $\beta$-catenin complexes from the cytoskeleton by oxidative stress. Biochem J 2002 368:471-481. PMID:12169098. PMCID:PMC1222996.

58. Seth A, Sheth P, Elias BC, Rao R. Protein phosphatases $2 A$ and 1 interact with occludin and negatively regulate the assembly of tight junctions in CACO-2 cell monolayer. $\mathrm{J}$ Biol Chem 2007 282:11487-11498. PMID:17298946.

59. Van Itallie CM, Anderson JM. Phosphorylation of tight junction transmembrane proteins: Many sites, much to do. Tissue Barriers 2018 6(1):e1382671. PMID:29083946.

PMCID:PMC5823547.

60. Furuse M, Sasaki H, Fujimoto K. Tsukita S. A single gene product, claudin-1 or -2, reconstitutes tight junction strands and recruits occludin in fibroblasts. J Cell Biol 1998b 143:391-401. PMID:9786950. PMCID:PMC2132845.

61. Sonoda N, Furuse M, Sasaki H, Yonemura S, Katahira J, Horiguchi Y, Tsukita S. Clostridium perfringens enterotoxin fragment removes specific claudins from tight junction strands: Evidence for direct involvement of claudins in tight junction barrier. J Cell Biol 1999 147:195-204. PMID:10508866. PMCID:PMC2164970.

62. Krug SM, Amasheh S, Richter JF, Milatz S, Guenzel D, Westphal JK, Huber O, Shulzke JD, Fromm M. Tricellulin forms a barrier to macromolecules in tricellular tight junctions without affecting ion permeability. Mol Biol Cell 2009 20:3713-3724. PMID:19535456.

63. Mrsny RJ, Brown GT, Gerner-Smidt K, Buret AG, Meddings JB, Quan C, Koval M, Nusrat A. A key claudin extracellular loop domain is critical for epithelial barrier integrity. Am J Pathol 2008 172:905-915. PMID:18349130. PMCID:PMC2276422.

64. Colegio OR, Van Itallie CM, McCrea HJ, Rahner C, Anderson JM. Claudins create chargeselective channels in the paracellular pathway between epithelial cells. Am J Physiol:Cell Physiol 2002 283:C142-C147. PMID:12055082.

65. Fromm M, Pinotek J, Rosenthal R, Gunzel D, Krug SM. Tight junctions of the proximal tubule and their channel proteins. Pfluegers Archiv-Europ J Physiol 2017 469:877-887. PMID:28600680.

66. Furuse M, Furuse K, Sasaki H, Tsukita S. Conversion of zonulae occludentes from tight to leaky strand type by introducing claudin-2 into Madin-Darby canine kidney I cells. J Cell Biol 2001 153:263-272. PMID:11309408. PMCID:PMC2169456. 
67. Van Itallie CM, Rogan S, Yu A, Vidal LS, Holmes J, Anderson JM. Two splice variants of claudin-10 in the kidney create paracellular pores with different ion selectivities. Amer J Physiol:Renal Physiol 2006 291:F1288-F1299. PMID:16804012.

68. Yu AS, Enck AH, Lencer WI, Schneeberger EE. Claudin-8 expression in Madin-Darby canine kidney cells augments the paracellular barrier to cation permeation. J Biol Chem 2003 278:17350-17359. PMID:12615928.

69. Van Itallie CM, Holmes J, Bridges A, Gookin JL, Coccaro MR, Proctor W, Colegio OR, Anderson JM. The density of small tight junction pores varies among cell types and is increased by expression of claudin-2. J Cell Sci 2008 121:298-305. PMID:18198187.

70. Amasheh S, Meiri N, Gitter AH, Schoeneberg T, Manketz J, Shulzke JD, Fromm M. Claudin2 expression induces cation-selective channels in tight junctions of epithelial cells. J Cell Sci 2002 115:4969-4976. PMID:12432083.

71. Tokuda S, Furuse M. Claudin-2 knockout by TALEN-mediated gene targeting in MDCK cells: claudin-2 independently determines the leaky property of tight junctions in MDCK cells. PLoS One 2015 10(3):e0119869. PMID:25781928.

72. Muto S, Hata M, Taniguchi J, Tsuruoka S, Moriwaki K, Saitou M, Furuse K, Sasaki H, Fujimura A, Imai M, Kusano E, Tsukita S, Furuse M. Claudin-2-deficient mice are defective in the leaky and cation-selective paracellular permeability properties of renal proximal tubules. Proc Natl Acad Sci USA 2010 107:8011-8016. PMID:20385797. PMCID:PMC2867900.

73. Irudayanathan FJ, Wang X, Wang N, Willsey SR, Seddon IA, Nangia S. Self-assembly simulations of classic claudins-Insights into the pore structure, selectivity, and higher order complexes. J Phys Chem B 2018 122:7463-7474. PMID:29869889.

74. Tamura A, Hayashi H, Imasato M, Yamazaki Y, Hagiwara A, Wada M, Noda T, Watanabe M, Suzuki Y, Tsukita S. Loss of claudin-15, but not claudin-2, causes $\mathrm{Na}^{+}$deficiency and glucose malabsorption in mouse small intestine. Gastroenterology 2011 140:913-922.

PMID:20727355.

75. Krug SM, Guenzel D, Conrad MP, Rosenthal R, Fromm A, Amasheh S, Shulzke JD, Fromm M. Claudin-17 forms tight junction channels with distinct anion selectivity. Cell Mol Life Sci 2012 69:2765-2778. PMID:22402829.

76. Milatz S, Krug SM, Rosenthal R, Guenzel D, Mueller D, Schulzke JD, Amasheh S, Fromm $\mathrm{M}$. Claudin-3 acts as a sealing component of the tight junction for ions of either charge and uncharged solutes. Biochim Biophys Acta 2010 1789:2048-2057. PMID:20655293.

77. Inai T, Kobayashi J, Shibata Y. Claudin-1 contributes to the epithelial barrier function in MDCK cells. Eur J Cell Biol 1999 78:849-855. PMID:10669103.

78. Guenzel D, Yu AS. Claudins and the modulation of tight junction permeability. Physiol Rev 2013 93:525-569. PMID:23589827.

79. Piontek A, Rossa J, Protze J, Wolburg H, Hempel C, Guenzel D, Krause G, Piontek J. Polar and charged extracellular residues conserved among barrier-forming claudins contribute to tight junction strand formation. Ann NY Acad Sci 2017 1397:143-156. PMID:28415153. 
80. Bruewer M, Hopkins AM, Hobert ME, Nusrat A, Madara JL. RhoA, rac1, and cdc42 exert distinct effects on epithelial barrier via selective structural and biochemical modulation of junctional proteins and F-actin. Am J Physiol:Cell Physiol 2004 287:327-335. PMID:15044152.

81. Buschmann MM, Shen L, Rajapakse H, Raleigh DR, Wang Y, Wang Y, Lingaraju A, Zha J, Abbott E, McAuley EM, Breskin LA, Wu L, Anderson K, Turner JR, Weber CR. Occludin OCELdomain interactions are required for maintenance and regulation of the tight junction barrier to macromolecular flux. Mol Biol Cell 2013 24:3056-3068. PMID:23924897. PMCID:PMC3784380.

82. Cao M, Wang P, Sun C, He W, Wang F. Amelioration of IFN-g and TNF-a-induced intestinal epithelial barrier dysfunction by berberine via suppression of MLCK-MLC phosphorylation signaling pathway. PLoS One 2013 8(5):e61944. PMID:23671580.

83. Jin Y, Blikslager AT. Myosin light chain kinase mediates intestinal barrier dysfunction via occludin endocytosis during anoxia/reoxygenation injury. Am J Physiol:Cell Physiol 2016 311:C996-C1004. PMID:27760753.

84. Oshima T, Miwa H, Joh T. Aspirin induces gastric epithelial barrier dysfunction by activating p38MAPK via claudin-7. Am J Physiol:Cell Physiol 2008 295:C800-C806. PMID:18667601.

85. Weber CR, Raleigh DR, Su L, Shen L, Sullivan EA, Wang Y, Turner JR. Epithelial myosin light chain kinase activation induces interleukin-13 expression to alter tight junction ion selectivity. J Biol Chem 2010 285:12037-12046. PMID:20177070. PMCID:PMC2852941.

86. Hasegawa H, Fujita H, Katoh H, Aoki J, Nakamura K, Ichikawa A, Negishi M. Opposite regulation of transepithelial electrical resistance and paracellular permeability by Rho in MadinDarby canine kidney cells. J Biol Chem 1999 274:20982-20988. PMID:10409646.

87. Watson CJ, Hoare CJ, Garrod DR, Carlson GL, Warhurst G. Interferon-gamma selectively increases epithelial permeability to large molecules by activating different populations of paracellular pores. J Cell Sci 2005 118:5221-5230. PMID:16249235.

88. Van Itallie CM, Fanning AS, Holmes J, Anderson JM. Occludin is required for cytokineinduced regulation of tight junction barriers. J Cell Sci 2010 123:2844-2852. PMID:20663912.

89. Carattino MD, Prakasam HS, Ruiz WG, Clayton DR, McGuire M, Gallo LI, Apodaca G. Bladder filling and voiding affect umbrella cell tight junction organization and function. $A m \mathrm{~J}$ Physiol:Renal Physiol 2013 305:F1158-F1168. PMID:23884145.

90. MercadoJ, Valenzano MC, Jeffers C, Sedlak J, Cugliari MK, Papanikolaou E, Clouse J, Miao J, Wertan NE, Mullin JM. Enhancement of tight junctional barrier function by micronutrients: Compound-specific effects on permeability and claudin composition. PLoS One 2013 8(11):e78775. PMID:24236048.

91. Janosevic D, Axis J, Bacallao RL, Amsler K. Occludin content modulates hydrogen peroxide-induced increase in renal epithelial paracellular permeability. J Cell Biochem 2015 117:769-779. PMID:26348235.

92. Anderson JM, Van Itallie CM. Physiology and function of the tight junction. Cold Spring Harb Perspect Biol 2009 1(2):a002584. PMID:20066090. PMCID:PMC2742087. 
93. Raya-Sandino A, Castillo-Kauil A, Dominguez-Calderon A, Alarcon L, Flores-Benitez D, Cuellar-Perez F, Lopex-Bayghen B, Chavez-Munguia B, Vazquez-Prado J, Gonzalez-Mariscal

$\mathrm{L}$. Zonula occludens-2 regulates Rho proteins activity and the development of epithelial cytoarchitecture and barrier function. BBA-Mol Cell Res 2017 1864:1714-1733. PMID:28554775.

94. Adson A, Raub TJ, Burton PS, Barsuhn CL, Hilgers AR, Audus KL, Ho NF. Quantitative approaches to delineate paracellular diffusion in cultured epithelial cell monolayers. J Pharm Sci 1994 83:1529-1536. PMID:7891269.

95. Kim K-J, Crandall ED. Heteropore populations of bullfrog alveolar epithelium. J Appl Physiol Respir Environ Exerc Physiol 1983 54:140-146. PMID:6600738

96. Renkin EM. Filtration, diffusion, and molecular sieving through porous cellulose membranes. J Gen Physiol 1954 38:225-243. PMID:13211998.

97. Hamalainen KM, Kontturi K, Auriola S, Murtomaki L, Urtii A. Estimation of pore size and pore density of biomembranes from permeability measurement of polyethylene glycols using an effusion-like approach. J Control Release 1997 49:97-104.

98. Kawedia JD, Jiang M, Kulkarni A, Waechter HE, Matlin KS, Pauletti GM, Menon AG. The Protein Kinase A pathway contributes to $\mathrm{Hg}^{2+}$-induced alterations in phosphorylation and subcellular distribution of occludin associated with increased tight junction permeability of salivary epithelial cell monolayers. J Pharm Exptl Therap 2008 326:829-837. PMID:18550693. PMCID:PMC2677297.

99. Cavanaugh KJ, Cohen TS, Margulies SS. Stretch increases alveolar epithelial permeability to uncharged micromolecules. Am J Physiol Cell Physiol 2006 290:C1179-C1188.

PMID:16282193.

100. Caswell D, Jaggi S, Axis J, Amsler K. Src family kinases regulate renal epithelial paracellular permeability barrier through an occludin-independent mechanism. J Cell Physiol 2013 228: 1210-1220. PMID:23129414.

101. Schulzke JD, Gitter AH, Mankertz J, Spiegel S, Seidler U, Amasheh S, Saitou M, Tsukita S, Fromm M. Epithelial transport and barrier function in occludin-deficient mice. Biochim Biophys Acta 2005 1669:34-42. PMID:15842997.

102. Saitou M, Fujimoto K, Doi Y, Itoh M, Fujimoto T, Furuse M, Takano H, Noda T, Tsukita S. Occludin-deficient embryonic stem cells can differentiate into polarized epithelial cells bearing tight junctions. J Cell Biol 1998 141: 397-408. PMID:9548718.

103. Yu ASL, McCarthy KM, Francis SA, McCormack JM, Lai J, Rogers RA, Lynch RD, Schneeberger EE. Knockdown of occludin expression leads to diverse phenotypic alterations in epithelial cells. Am J Physiol:Cell Physiol 2005 288:C1231-C1241. PMID:15689410.

104. Bilal S, Jaggi S, Janosevic D, Shah N, Teymour S, Voronina A, Watari J, Axis J, Amsler K. ZO-1 protein is required for hydrogen peroxide to increase MDCK cell paracellular permeability in an ERK 1/2-dependent manner. Am J Physiol Cell Physio 2018 315:C422-C431.

PMID:29874107 
105. Richter JF, Hildner M, Schmauder R, Turner JR, Schumann M, Reiche J. Occludin knockdown is not sufficient to induce transepithelial macromolecule passage. Tissue Barriers 2019 4:1-14. PMID:31161924.

106. Balda MS, Whitney JA, Flores C, Gonzalez S, Cereijido M, Matter K. Functional dissociation of paracellular permeability and transepithelial electrical resistance and disruption of the apical-basolateral intramembrane diffusion barrier by expression of a mutant tight junction membrane protein. J Cell Biol 1996 134:1031-1049. PMID:8769425.

107. McCarthy KM, Skare IB, Stankewich MC, Furuse M, Tsukita S, Rogers RA, Lynch RD, Schneeberger EE. Occludin is a functional component of the tight junction. J Cell Sci 1996 109:2287-2298. PMID:8886979.

108. Al-Sadi R, Khatib K, Guo S, Ye D, Youssef M, Ma T.. Occludin regulates macromolecular flux acrsss the intestinal epithelial tight junction barrier. Am J Physiol:Gastrointest Liver Physiol 2011 300:G1054-G1064. PMID:21415414.

109. Marchiando AM, Shen L, Graham WV, Weber CR, Schwartz BT, Austin Jr 2 ${ }^{\text {nd }}$, Raleigh DR, Guan Y, Watson AJ, Montrose MH, Turner JR. Caveolin-1-dependent occludin endocytosis is required for TNF-induced tight junction regulation in vivo. J Cell Biol 2010 189:111-126.

PMID:20351069.

110. Balda MS, Flores-Maldonado C, Cereijido M, Matter K. Multiple domains of occludin are involved in regulation of paracellular permeability. J Cell Biochem 2000 78:85-96.

PMID:10797568.

111. Wong V, Gumbiner BM. A synthetic peptide corresponding to the extracellular domain of occludin perturbs the tight junction permeability barrier. J Cell Biol 1997 136:399-409.

PMID:9015310. PMCID:PMC2134825.

112. Krug SM. Contribution of the tricellular tight junction to paracellular permeability in leaky and tight epithelia. Ann NY Acad Sci 2017 1397:219-230. PMID:28605032.

113. Mandell KJ, Babbin BA, Nusrat A, Parkos CA. Junctional adhesion molecule 1 regulates epithelial cell morphology through effects on beta1 integrins and Rap1 activity. J Biol Chem 2005 280:11665-11674. PMID:15677455.

114. Laukoetter MG, Nava P, Lee WY, Severson EA, Capaldo CT, Babbin BA, Williams IR, Koval M, Peatman E, Campbell JA, Dermody TS, Nusrat A, Parkos CA. JAM-A regulates permeability and inflammation in the intestine in vivo. J Exp Med 2007 204:3067-3076. PMID:18039951.

115. Monteiro AC, Sumagin R, Rankin CR, Leoni G, Mina MJ, Reiter DM, Stehle T, Dermody TS, Schaefer SA, Hall RA, Nusrat A, Parkos CA. JAM-A associates with ZO-2, afadin, and PDZGEF1 to activate Rap2c and regulate epithelial barrier function. Mol Biol Cell 2013 24:28492860. PMID:23885123.

116. Tokuda S, Higashi T, Furuse M. ZO-1 knockout by TALEN-mediated gene targeting in MDCK cells: involvement of ZO-1 in the regulation of cytoskeleton and cell shape. PLoS One 2014 9(8)e104994. PMID:25157572. 
117. Hernandez S, Munguia BC, Gonzalez-Mariscal L. ZO-2 silencing in epithelial cells perturbs the gate and fence function of tight junctions and leads to an atypical monolayer architecture. Exp Cell Res 2007 313:1533-1547. PMID:17374535.

118. Fanning AS, Van Itallie CM, Anderson JM. Zonula occludens-1 and -2 regulate apical cell structure and the zonula adherens cytoskeleton in polarized epithelia. Mol Biol Cell 2012 23:577-590. PMID:22190737.

119. Rodgers LS, Beam MT, Anderson JM, Fanning AS. Epithelial barrier assembly requires coordinated activity of multiple domains of the tight junction protein ZO-1. J Cell Sci 2013 126:1565-1575. PMID:23418357. PMCID:PMC3647435.

120. Cunningham KE, Turner JR. Myosin light chain kinase: pulling the strings of epithelial tight junction function. Ann NY Acad Sci 2012 1258:35-42. PMID:22731713.

121. Quiros M, Nusrat A. RhoGTPases, actomyosin signaling and regulation of the epithelial Apical Junctional Complex. Semin Cell Dev Biol 2014 36:194-203. PMID:25223584.

122. Rodgers LS, Fanning AS. Regulation of epithelial permeability by the actin cytoskeleton. Cytoskeleton 2011 68:653-660. PMID:22083950.

123. Liu S, Xiong X, Zhao X, Yang X, Wang H. F-BAR family proteins, emerging regulators for cell membrane dynamic changes - from structure to human disease. J Hematol Oncol 2015 8:47. PMID:25956236.

124. Richter JF, Schmauder R, Krug SM, Gebert A, Schumann M. A novel method for imaging sites of paracellular passage of macromolecules in epithelial sheets. J Controlled Release 2016 229:70-79. PMID:30040167.

125. Stephenson RE, Higashi T, Erofeev IS, Arnold TR, Leda M, Goryachev AB, Miller AL. Rho flares repair local tight junction leaks. Devel Cell 2019 48:445-459. PMID:30773490.

126. Cohen TS, Cavanaugh KJ, Margulies SS. Frequency and peak stretch magnitude affect alveolar epithelial permeability. Eur Respir J 2008 32:854-861. PMID:18614557.

127. Cohen TS, Gray Lawrence G, Khasgiwala A, Margulies SS. MAPK activation modulates permeability of isolated rat alveolar epithelial cell monolayers following cyclic stretch. PLoS One 2010 5(4):e10385. PMID:20442784.

128. DiPaolo BC, Margulies SS. Rho kinase signaling pathway during stretch in primary alveolar epithelia. Am J Physiol Lung Cell Mol Physiol 2012 302:L992-L1002. PMID:22287611.

129. Samak G, Gangwar R, Crosby LM, Desai LP, Wilhelm K, Waters CM, Rao R. Cyclic stretch disrupts apical junctional complexes in Caco-2 cell monolayers by a JNK-2-, C-Src, and MLCKdependent mechanism. Am J Physiol Gastrointest Liver Physiol 2014 306:G947-G958. PMID:24722904.

130. Samak G, Suzuki T, Bhargava A, Rao RK. c-Jun NH2-terminal kinase-2 mediates osmotic stress-induced tight junction disruption in the intestinal epithelium. Am J Physiol Gastrointest Liver Physiol 2010 299:G572-G584. PMID:20595622. 
131. Cattaneo I, Condorelli L, Terrinoni AR, Antiga L, Sangalli F, Remuzzi A. Shear stress reverses dome formation in confluent renal tubular cells. Cell Physiol Biochem 2011 28:673682. PMID:22178879.

132. Acharya BR, Nestor-Bergmann A, Liang X, Gupta S, Duszyc K, Gauquelin E, Gomez GA, Budnar S, Marcq P, Jensen OE, Bryant Z, Yap AS. A mechanosensitive RhoA pathway that protects epithelia against acute tensile stress. Devel Cell 2018 47:439-452. PMID:30318244.

133. Terry SJ, Zihni C, Elbediwy A, Vitiello E, Leefa Chong San IV, Balda MS, Matter K. Spatially restricted activation of RhoA signaling at epithelial junctions by 114 RhoGEF drives junction formation and morphogenesis. Nat Cell Biol 2011 13:159-166. PMID:21258369.

134. Sabath E, Negoro H, Beaudry S, Paniagua M, Angelow S, Shah J, Grammatikakis N, Yu AS, Denker BM. Galpha12 regulates protein interactions within the MDCK cell tight junction and inhibits tight junction assembly. J Cell Sci 2008 121:814-824. PMID:18285450.

135. Acharya BR, Wu SK, Lieu ZZ, Parton RG, Grill SW, Bershadsky AD, Gomez GA, Yap AS. Mammalian Diaphanous 1 mediates a pathway for E-cadherin to stabilize epithelial barriers through junctional contractility. Cell Reports 2017 18:2854-2867. PMID:28329679.

136. Spadaro D, Le S, Laroche T, Mean I, Jond L, Yan J, Citi S. Tension-dependent stretching activates ZO-1 to control the junctional localization of its interactors. Curr Biol 2017 27:37833795. PMID:29199076.

137. Yonemura S, Wada Y, Watanabe T, Nagafuchi A, Shibata M. Alpha-catenin as a tension transducer that induces adherens junction development. Nat Cell Biol 2010 12:533-542. PMID:20453849.

138. Buckley A, Turner JR. Cell biology of tight junction barrier regulation and mucosal disease. Cold Spring Harb Perspect Biol 2018 10(1):a029314. PMID:28507021.

139. Krystofiak ES, Heymann JB, Kachar B. Carbon replicas reveal double stranded structure of tight junctions in phase-contrast electron microscopy. Comm Biol 2019 2:98. PMID:30886907.

140. Suzuki H, Tani K, Tamura A, Tsukita S, Fujiyoshi Y. Model for the architecture of claudinbased paracellular ion channels through tight junctions. J Mol Biol 2015 427:291-297. PMID:25451028.

141. Manda B, Mir H, Gangwar R, Meena AS, Shukla PK, Dalal K, Suzuki T, Rao R. Phosphorylation hotspot in the C-terminal domain of occludin regulates the dynamics of epithelial junctional complexes. J Cell Sci 2018 131(7). Pii:jcs206789. PMID:29507118. PMCID:PMC5963837.

142. Shen L, Weber CR, Turner JR. The tight junction protein complex undergoes rapid and continuous molecular remodeling at steady state. J Cell Biol 2008 181:683-695.

PMID:18474622.

143. Yu D, Marchiando AM, Weber CR, Raleigh DR, Wang Y, Shen L, Turner JR. MLCKdependent exchange and actin binding region-dependent anchoring of ZO-1 regulate tight junction barrier function. Proc Natl Acad Sci USA 2010 107:8237-8241. PMID:20404178. 
